\title{
Correction
}

\section{Blood pressure: at what level is treatment worthwhile? [Correction]}

Aust Prescr 2020:43:33

https://doi.org/10.18773/austprescr.2019.078

First published 19 December 2019

The article on blood pressure treatment (Aust Prescr 2019;42:127-30) has been corrected. View corrected article.

The Table comparing international guidelines for the treatment of hypertension (p.128) misquoted the US starting point for the general population as $\geq 140 / 80 \mathrm{mmHg}$. It should have read $\geq 140 / 90$.

\section{EDITORIAL OFFICE}

For general correspondence such as Letters to the Editor, contact the Editor.

\section{Postal The Editor}

Australian Prescriber

Level 5, 15 Moore Street

Canberra, ACT 2600

Telephone +61282178700

Email info@australianprescriber.com

Website nps.org.au/australian-prescriber

Twitter@AustPrescriber

\section{SUBSCRIPTIONS}

Australian Prescriber is published every two months online. All content is accessible free of charge in full text at nps.org.au/ australian-prescriber. New drugs are published between issues as they become available.

An email alert can be sent to you when Australian Prescriber publishes new material. Subscribe or update your details at nps.org.au/australian-prescriber

For free copies of the Anaphylaxis wallchart and Switching-antidepressants poster, order online at www.nps.org.au/order\#for-health-professionals (c) 2020 NPS MedicineWise ABN 61082034393

NPS MedicineWise Disclaimer Reasonable care is taken to provide accurate information at the time of creation. This information is not intended as a substitute for medical advice and should not be exclusively relied on to

manage or diagnose a medical condition. NPS MedicineWise disclaims all liability (including for negligence) for any loss, damage or injury resulting from reliance on or use of this information. 